\title{
All eyes on Sudan: The journey of female psychologists in the theatre of operation
}

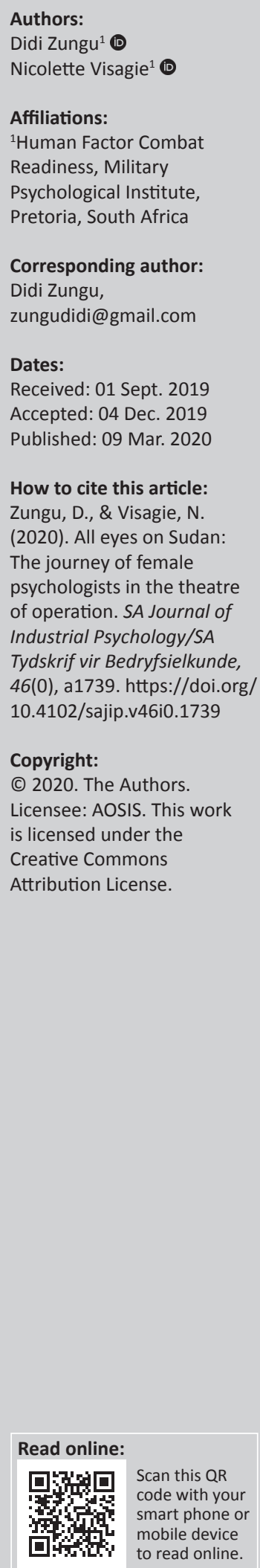

Orientation: South African National Defence Force (SANDF) psychologists fulfil one of the most challenging roles within the psychological profession when deployed in peacekeeping operations (PKOs).

Research purpose: This study aimed at gaining an in-depth understanding of the experiences of female military psychologists during deployment in a PKO in the Darfur region.

Motivation for the study: The study aimed to gain an insight into the unique experiences of female SANDF psychologists in the theatre of operation (deployment area) and to create a body of knowledge regarding SANDF psychologists' deployment experiences, with specific reference to female psychologists.

Research design/approach and method: A case study approach informed the framework for the study set against the backdrop of a qualitative, constructivist, hermeneutic research paradigm. Written personal accounts were evoked through visuals or photographic materials, obtained during in-depth interviews. Researchers used content analysis, and developed themes and subthemes with the use of an open-coding approach.

Main findings: Three main themes were elicited: deployment experiences, peacekeeping deployment experiences and experiences of female psychologists. Each theme was supported by four subthemes.

Practical/managerial implications: The study facilitated an increased understanding of the personal impact of PKO experiences on the journey of female psychologists serving in the SANDF in Darfur.

Contribution/value-add: This research provides a platform for the sharing and understanding of the unique experiences of health care workers of the SANDF deployed in the mission area, with specific reference to female psychologists. This co-created understanding acts as a space where psychologists can share a community for support if required post-deployment.

Keywords: female psychologists; SANDF; peacekeeping; qualitative; Darfur.

Because you can name something does not mean you understand it. Because you understand it does not mean it can be named. (Halcolm, as cited in Patton, 2002, p. 429)

\section{Introduction}

Deployed military psychologists fulfil one of the most challenging roles within professional psychology (Ghimire, 2017; Laurence, Milavec, Rohall, Ender, \& Matthews 2016; Linnerooth, Mrdjenovich, \& Moore, 2011). These challenges mainly stem from a dualistic role where serving psychologists have to take care of themselves amidst the isolation, myriad of deployment-related stressors, and also provide psychological care to members of the defence force at large. Psychologists functioning in operational roles therefore work in one of the most complex settings, with multiple commitments, roles and varying cultural conditions (Johnson \& Kennedy, 2010; Moore \& Reger, 2006).

Military psychologists in the frontline historically play a significant role in supporting soldiers (McCauley, Hughes, \& Liebling-Kalifani, 2008). In line with this historical role, the core duties of South African National Defence Force (SANDF) psychologists during peacekeeping operations (PKOs) are varied depending on their registration categories and the mission specifics. The core functions during peacekeeping missions include psychological support, tailor-made interventions, preventative psychological education during the mission, command consultation, team building, timeous identification of members displaying potential psychological risk factors, field research into behavioural dynamics and monitoring of leadership effectiveness. Therefore, the contribution psychologists provide in support of members within operational areas is critical, and psychologists are 
viewed as force multipliers (Heinecken \& Ferreira, 2012c). The role of frontline psychologists requires military psychologists to be excellent generalists in contexts where they often find themselves as the sole mental health service providers to a large battalion (Johnson, 2008). Considering the unique role that military psychologists fulfil, and the myriad of unique stressors they experience, the possibility exists that female psychologists might further face qualitatively different experiences and stressors in these types of settings (Raju, 2014).

\section{Literature review Deployment experiences worldwide}

Deployment experiences of combat soldiers have been welldocumented throughout history. Psychological research has focussed on experiences from as early on as the Vietnam War (1955-1975) to more modern accounts of war such as the IranIraq War in the 1980s, the Gulf War in the 1990s and Operation Enduring Freedom in Afghanistan (2001-2014). The focus of traditional research into the deployment experiences of soldiers on the frontline is mainly on the adverse effects of combat and stressors experienced during combat. These includeexperiences of being shot and wounded or having witnessed atrocities, as well as the death of a fellow soldier (Born \& Zamorski, 2019). Psychological research on these experiences usually culminates in the understanding and treatment of post-traumatic stress disorder (PTSD) (Orme \& Kehoe, 2014). Therefore, limited qualitative accounts depicting the subjective experiences of soldiers exist within the literature. Bartone et al. (1998) noted that stressors during PKO internationally belong to the stress-related nosology and have characteristics pertaining to: the degree of enforcement, length of mission, amount of chaos, acceptance by the local people and attacks from the local force. From these characteristics, he developed five dimensions of psychological stress that peacekeepers face. These are: isolation, ambiguity, powerlessness, danger or threat, and boredom (Bartone, Adler, \& Vaitkus, 1998). Rollero and De Sanctis (2019) conducted a study on the experiences of Italian male peacekeepers, and the five themes elicited from the narratives were: the motivation to participate in an operation; the group as a buffer against combat-related stress; the hardest aspects of the experience; coping strategies towards the mission, perceived as a life-or-death experience; and benefits and negative consequences after going back home.

In line with soldiers' experiences during wartime, research conducted on the experiences of combat medics resonates strongly with their non-medical counterparts. Therefore, whilst they experience feelings of being in serious danger, the fear of injury or death and losing a fellow soldier, they also contend with personally being required in extreme circumstances to engage the enemy. Furthermore, as a result of their core duties, they are exposed to additional trauma, such as seeing civilians, soldiers and allies or enemy combatants severely wounded, disfigured or killed in combat, which further adds to the burden they face (Chapman et al., 2012). The medics therefore have a dualistic role, one where they are medics and one where they are soldiers.
Mark et al. (2009) provided an understanding of medical personnel's experiences during deployment. Their study generated themes related to: leadership; care for subordinates; care for patients; readiness; half-ready medics or soldiers; broken soldiers; broken system; and just-in-time health care. These experiences suggest that they have to contend with an extra burden of being both a soldier and a caregiver during deployments, and allude to the difficulties they experience during deployment.

\section{Deployment experiences in Africa}

Deployment experiences in Africa have been mostly concerned or related to $\mathrm{PKO}$, since the inception of these missions in 1948. Most of the literature regarding these experiences is focussed on postulating different overarching descriptive categories to encapsulate the overall experiences reported by soldiers. These categories are utilised to understand and explore the nature of the experiences of soldiers during PKOs.

Raju (2014) categorised the experiences of soldiers into various 'experience dimensions', namely, subjectiveobjective, traumatic-non-traumatic and commonuncommon experiences. Other researchers aimed at including both the psychological impact on the individual as well as the family functioning (Kgosana \& Van Dyk, 2011). In addition, Campbell and Nobell (2009) proposed all-encompassing categories focussing on potential stressors according to work, social-interpersonal family, self-identity, psychological environment, cultural environment and physical environment, whilst also expanding these categories by appraising them within environments (combat versus garrison environments) as well as linking these experiences to deployment-specific phases.

Literature regarding the unique experiences of psychologists during PKO internationally, as well as in the African context has not been documented extensively and remains elusive.

\section{Females and deployment}

In line with the elusive nature of the experiences of psychologists in $\mathrm{PKO}$, the specific unique experiences of female psychologists have not yet been investigated. In recent times, the United Nations (UN) has called for greater deployment of female peacekeepers to enhance the overall 'holistic' approach to current UN PKO and to this end the UN Security Council adopted Resolution 1325 on Women and Peace in October 2000. This contributes to the notion that more skilled and trained female peacekeepers can be an asset to future PKO (Ghimire, 2017; Hutabarat, 2017). As a result of this view of the UN, women are increasingly serving their country as soldiers, airmen and sailors (Laurence et al., 2016). The increasing non-traditional roles taken up by women and reliance on women in deployment as part of the fighting force is an ever-growing discussion (Matthews, Morten, Laurence, \& Rohall, 2009). Furthermore, considering the 
increased feminisation of the profession of psychology, it is not surprising that female psychologists are now also represented in the theatre of operation. Heinecken (2016) reported that the SANDF comprised 24\% women, with $15 \%$ of them deployed on PKO, which makes South Africa the leading military in Africa in terms of female representatives. In light of the above, more female SANDF psychologists are being deployed in PKOs.

It is commonly denoted that female and male soldiers are exposed to similar operational and combat-related stressors on physiological as well as a psychological dimensions. However, it is accepted that a case can be made that female soldiers might experience combat and operation-related stressors in a unique manner (Visagie, 2018). These stressors can broadly be delineated into intrinsic stressors, including physiological and psychological stressors; extrinsic stressors, including the sexual dimension, gender-violence dimension, family dimension and organisational stressors, including cohesion and career development. Physiologically, female soldiers generally do not have the same physical abilities as their male counterparts in terms of strength and endurance (Maitra, 2013). Psychologically, higher prevalence of mental health risk related to PTSD, depression and anxiety is reported amongst female soldiers (Tarrash, Lurie, Yanovich, \& Moran, 2011). In terms of the extrinsic stressors, females may be exposed to sexual coercion, gender-based violence and the associated traumas. Furthermore, they have to contend and balance the dual roles of being the primary care giver to their families and that of a soldier (King, 2013; Mattocks et al., 2012; Simic, 2010).

In terms of the organisational dimension, females are seen as detracting from the unit cohesion or togetherness of the soldiers by altering the group dynamics. With regard to the career development dimension, female soldiers are rapidly promoted, or provided preference for course acceptances, in accordance with gender transformation guidelines and policies. This sets the tone for the view that female soldiers are often labelled as 'quota' soldiers (SANDF, 2015).

\section{South African National Defence Force psychologists: The Darfur context}

The SANDF is unique within the African context as South Africa is the only troop-contributing country, which deploys a contingent psychologist with each battalion deployed for various missions, such as the African Union (AU-), UN- or Southern African Development Community (SADC)-specific missions. On entering the military system, the transition from civilian life to that of a military psychologist is often a function of military deployment, where the psychologist is exposed to the military way of life for the first time. Therefore, it is not a given that a SANDF psychologist would have had any military training prior to deployment. The psychologist is therefore bombarded with different contexts that they have to function within. These contexts include: (1) the military context; (2) rules and regulations that they are not fully conversant with; (3) the military psychological context, where the psychologist is faced with military-specific trauma; and the (4) dual nature of the deployment context, in this case the Darfur region, which is a completely new system, with foreign cultural aspects, values, ideologies and beliefs.

The hostility in Darfur is characterised by religious and conservative underpinnings and is considered a strong patriarchal system (Koopman \& Van Dyk, 2012). Heinecken and Ferreira (2012a) stated that the conflict in this region has been labelled 'the worst humanitarian and human rights catastrophe in the world', where women and children are often the victims of the conflict. This is in direct contrast with the 'lifeworld' of the SANDF soldier, where the South African constitution and culture are in direct contrast with the culture in the Darfur region. This is the backdrop of the dichotomous and paradoxical systems wherein SANDF psychologists are deployed (Kennedy \& Zilmer, 2012).

South African military psychologists differ vastly from their combatant counterparts. The differences include: (1) military training, where little or no military training is required to be deployed; (2) the separate nature of the medical task group the psychologists are embedded in the medical group, and they have little cohesion with the others in this group prior to deployment because of limited integration training; and (3) different levels of prior soldiering experiences (Bartone \& Adler, 2000). Research focussing on military mental health practitioners identified the following main challenges on deployment: (1) to fit in and attain a sense of belonging when working with a branch of service different from their own; (2) limited resources; and (3) ethical challenges that arise from having multiple role dilemmas and maintaining confidentiality (Miller \& Warner, 2013). The SANDF does not provide a limitation on the registration category of the deployed psychologist. This implies an additional challenge for the deployed psychologist of being faced with situations that fall outside the realm of their specified registration category, contributing to work-related pressure.

\section{Research purpose}

This article aims at gaining an in-depth understanding of the experiences of SANDF psychologists deployed to the Darfur region in Sudan. From this understanding, the objective is to develop awareness within the military psychological fraternity on the challenges and experiences that are unique to psychologists as well as to create a platform for psychologists to share their experiences in order to create a shared community.

\section{Research objective}

Limited research on the experiences of deployed psychologists is available internationally and within the South African context. The limited research extends to the Darfur region and Sudan, where little or no psychological research on soldiers' experiences is found. Furthermore, as psychology is 
viewed as an increasingly feminised profession, the possibility exists for more female psychologists being deployed to mission areas where the culture is patriarchal and conservative with regard to women's rights. Considering all the above trends, it is critical that these experiences are documented in order to inform preparation of psychologists prior to their deployment as well as create a platform for the sharing of experiences post-deployment.

\section{Research design \\ Research approach and strategy}

A qualitative research approach was utilised to generate an in-depth, multi-faceted understanding of the complex issue of female psychologists deployed to the Darfur region for supporting SANDF soldiers. The study uses a hermeneutic research paradigm as the framework (Guba \& Lincoln, 1994). The researchers endeavoured to create meaning from their experiences through analysis, description and interpretation of participants' individual, written personal accounts, which were obtained specifically for the purpose of the research. In order to obtain detailed emotional descriptions from the participants, these individuals selected photographic material, which represented their deployment experience, and a written description of each photo was provided by them during in-depth interviews.

\section{Research method \\ Research setting}

At the time of the interviews, participants worked in the SANDF, holding the positions of psychologists, one as an industrial psychologist and one as a clinical psychologist. The interviews pertained specifically to their deployment experiences in the Darfur region of Sudan. The participants became the researchers. Upon return from deployment, it is normal for soldiers to experience some challenges readjusting after their return from the operational area. It was no different for the participants. The unique deployment experiences could only be understood by a fellow female psychologist with similar deployment experiences. A narrative approach naturally developed from the post-deployment adjustment process, which initiated a formal research process that took place over a period of 3 years.

\section{Sampling}

Both psychologists were operationally deployed for longer (7 months) than their prescribed time of 3 months to the Darfur region in Sudan. The two participants were sampled purposefully (Neuendorf, 2002), based on gender (female), position (psychologist) and length of deployment (exceeding a 6-month period). The focus is on gaining an in-depth understanding of this specialised and limited population (Denzin \& Lincoln, 1994). The two women were both white and 32 years of age at the time of deployment, with limited formal military training at the time of their tour of duty.

\section{Data collection methods and recording}

Data was collected from both participants utilising their individual written personal accounts which was evoked through visual, photographic material. Individual participants were requested to select meaningful photos from the deployment. Then, they narrated what each photo represented to them in writing. The intensity of the emotional experience underlying the data required a patient approach and increased the timeframe for data collection. Photographic stimuli were introduced to counteract the occupational tendency of resistance when sourcing personal data from psychologists. Participant 1 submitted 76 photos and participant 2 provided 53 photos; written accounts were collected for each of these during extended in-depth interviews that took place over a 6-month period. Relevant biographical data were collected during this process, and the data were stored electronically.

\section{Data analyses}

The researchers utilised content analysis, which provided a systematic, in-depth approach to conceptualise and understand (Babbie \& Mouton, 2010) the experiences of female psychologists during long deployments. The researchers developed themes and subthemes; then an open-coding approach was used. Data analysis was conducted by hand. Tables and figures were utilised to display the themes and subthemes. A reflexive stance was taken, which included regular, ongoing self-conscious documentation of successive versions of coding schemes, themes, arguments between analysts and the final display of data.

\section{Strategies to ensure quality data}

To enhance quality and credibility, the first strategy employed was triangulation of the data; the researchers furthermore utilised a third objective researcher to assess the consistency of the data obtained (Patton, 2002). This researcher is a colleague who has not been deployed to the Darfur region, which allowed an objective stance; the participants or researchers however chose the objective independent researcher as he or she was considered trustworthy to enable the participants to share their 'raw' narratives and 'data' with the objective researcher. As the researchers had a subjective and participatory interest in the data, this allowed for analysis and the depth of the information to be confirmed. Data quality checks furthermore included awareness and compliance with the applicable ethical frameworks, informed consent, rigorous analyses and constant comparison of the data (Denzin \& Lincoln, 1994).

\section{Reporting}

Findings are reported in a qualitative style, using thick, indepth descriptions of data, with contextualising information extracts from the written transcripts of participants. 


\section{Ethical consideration}

The study adhered to all ethical considerations and necessary approvals were obtained.

\section{Findings}

In the interest of clarity, the findings are reported in terms of three main themes, with the various subthemes related to each main theme (Figure 1).

The main themes include general deployment experiences, peacekeeping deployment experiences and unique female psychologist experiences. Rich, in-depth quotations are provided for each theme and related subthemes, with excerpts from both participants. The themes and subthemes with underlying photos coded per theme and per participant are reflected in Table 1.

\section{General deployment experiences}

This theme encapsulates experiences the participants reflected on which relates to typical soldiering experiences within a deployment context, irrespective of the function of the soldier or nature of the deployment. The four subthemes are discussed in detail below.

\section{Challenges of confinement}

Participant 1 refers to the environmental stressor of confinement, being constantly surrounded by people, with their watchful eyes observing every action:
'One of my favourite photos. Shows the barbed wire around the base. It shows the starkness of the barbed wire in the desert, as well as the confinement in the vast open space...there is so much space yet you are required to live in a small little piece in the middle of nowhere.' (P1, Ph 51)

Participant 2 similarly refers to the environmental stressor of confinement. The participant explained that confinement was a big thing; you are working and sleeping in the same space, you feel complete confinement, everyone can see everything that you are doing, how many times you go to the toilet, when you eat, everything! Even when you run, you run around and around the base, which emphasises restraint of movement:

'The focus is the barbed wire. The confinement, and the crows sitting, waiting for anything there. It feels like death is hanging in the air. It is the only way I can explain it. It is very eerie.' $(\mathrm{P} 2, \mathrm{Ph} 28)$

\section{Experiencing isolation}

During the interview, P1 explained the constant dichotomies experienced as a female psychologist in the deployment environment. Firstly, the extreme feeling of constantly being surrounded by people, yet living in isolation. Living with a large number of people, who remain within the boundaries of a fairly limited area within the base, it is inevitable that various groups are naturally formed. The different groups that can be identified are in-groups, female groups, medic groups, soldier groups and many more. Especially as a psychologist, you need to have access and be accessible to all

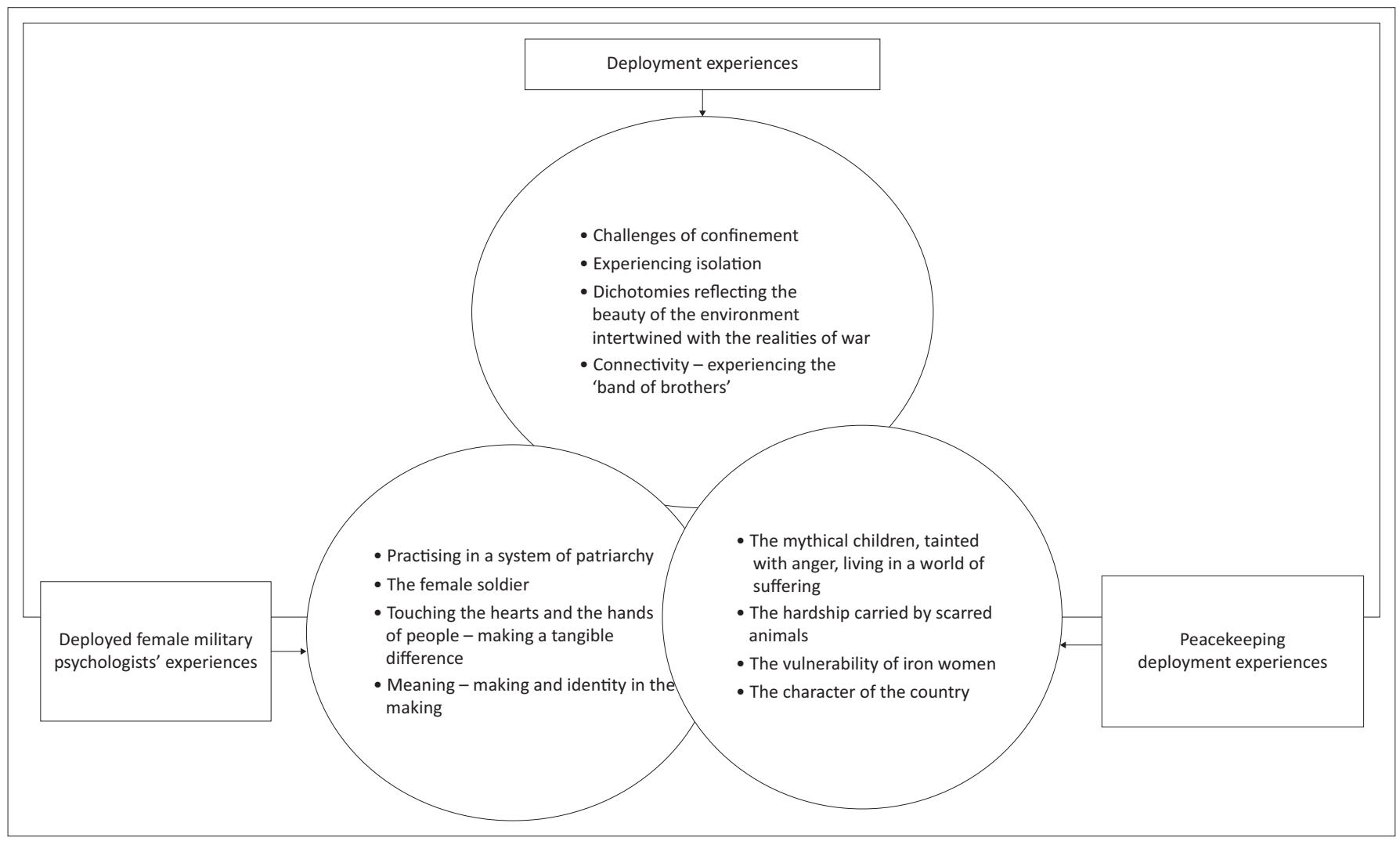

FIGURE 1: Integrated experiences of deployed female military psychologists. 
TABLE 1: Themes and subthemes of female psychologists' military deployment experiences.

\begin{tabular}{|c|c|c|c|}
\hline Theme & Subtheme & Participant & Photographic stimuli \\
\hline \multirow[t]{8}{*}{ Deployment experiences } & \multirow[t]{2}{*}{ Challenges of confinement } & P1 & Ph20, Ph27, Ph52, Ph53, Ph54, Ph66 \\
\hline & & P2 & $\mathrm{Ph} 2, \mathrm{Ph} 28, \mathrm{Ph} 42, \mathrm{Ph} 43$ \\
\hline & \multirow[t]{2}{*}{ Experiencing isolation } & P1 & $\mathrm{Ph} 12, \mathrm{Ph} 21, \mathrm{Ph} 46, \mathrm{Ph} 52, \mathrm{Ph} 56$ \\
\hline & & P2 & Ph1, Ph11, Ph20, Ph25, Ph53 \\
\hline & \multirow[t]{2}{*}{$\begin{array}{l}\text { Dichotomies reflecting the beauty of the environment } \\
\text { intertwined with the realities of war }\end{array}$} & P1 & $\begin{array}{l}\mathrm{Ph} 1, \mathrm{Ph} 2, \mathrm{Ph} 3, \mathrm{Ph} 4, \mathrm{Ph} 5, \mathrm{Ph} 6, \mathrm{Ph} 7, \mathrm{Ph} 12, \mathrm{Ph} 19, \mathrm{Ph} 22, \mathrm{Ph} 23, \mathrm{Ph} 27, \mathrm{Ph} 34, \mathrm{Ph} 47 \\
\mathrm{Ph} 62, \mathrm{Ph} 63, \mathrm{Ph} 64, \mathrm{Ph} 66\end{array}$ \\
\hline & & P2 & $\mathrm{Ph} 7, \mathrm{Ph} 21, \mathrm{Ph} 27, \mathrm{Ph} 29, \mathrm{Ph} 32, \mathrm{Ph} 37, \mathrm{Ph} 40, \mathrm{Ph} 41, \mathrm{Ph} 43, \mathrm{Ph} 45$ \\
\hline & \multirow[t]{2}{*}{ Connectivity - experiencing the 'band of brothers' } & P1 & Ph4, Ph16, Ph17, Ph18, Ph24, Ph26, Ph31, Ph72, Ph73, Ph74 \\
\hline & & P2 & Ph12, Ph13, Ph14, Ph24, Ph34, Ph38, Ph48, \\
\hline \multirow{7}{*}{$\begin{array}{l}\text { Peacekeeping deployment } \\
\text { experiences }\end{array}$} & \multirow{2}{*}{$\begin{array}{l}\text { The mythical children, tainted with anger, living in a } \\
\text { world of suffering }\end{array}$} & P1 & $\mathrm{Ph} 28, \mathrm{Ph} 35, \mathrm{Ph} 43, \mathrm{Ph} 44$ \\
\hline & & P2 & Ph3, Ph4, Ph8, Ph10, Ph18, Ph33, Ph47 \\
\hline & \multirow[t]{2}{*}{ The hardship carried by scarred animals } & P1 & Ph13, Ph37, Ph65, Ph70 \\
\hline & & P2 & $\mathrm{Ph} 1, \mathrm{Ph} 17, \mathrm{Ph} 39, \mathrm{Ph} 42, \mathrm{Ph} 44, \mathrm{Ph} 45$ \\
\hline & The vulnerability of iron women & P1 & $\mathrm{Ph} 29, \mathrm{Ph} 30, \mathrm{Ph} 32, \mathrm{Ph} 33, \mathrm{Ph} 68$ \\
\hline & \multirow[t]{2}{*}{ The character of the country } & P1 & Ph38, Ph40, Ph42, Ph48, Ph50, Ph69, Ph75 \\
\hline & & P2 & Ph5, Ph9, Ph19, Ph22, Ph23, \\
\hline \multirow{8}{*}{$\begin{array}{l}\text { Unique female psychologists' } \\
\text { experiences }\end{array}$} & \multirow[t]{2}{*}{ Practicing in a system of patriarchy } & P1 & $\mathrm{Ph} 25, \mathrm{Ph} 29, \mathrm{Ph} 30, \mathrm{Ph} 45$ \\
\hline & & P2 & $\mathrm{Ph} 6, \mathrm{Ph} 31, \mathrm{Ph} 48, \mathrm{Ph} 50$ \\
\hline & \multirow[t]{2}{*}{ The female soldier } & P1 & Ph8, Ph9, Ph11, Ph14, Ph15, Ph21, Ph49, Ph50, Ph55, Ph57, Ph58, Ph59, Ph61, Ph71 \\
\hline & & P2 & Ph15, Ph16, Ph30, Ph31, Ph35, Ph36, Ph45, Ph46 \\
\hline & \multirow{2}{*}{$\begin{array}{l}\text { Touching the hearts and hands of people - making a } \\
\text { tangible difference }\end{array}$} & P1 & Ph6, Ph7, Ph10, Ph32, Ph33, Ph36, Ph39, Ph41, \\
\hline & & P2 & $\mathrm{Ph} 19, \mathrm{Ph} 32, \mathrm{Ph} 33, \mathrm{Ph} 49, \mathrm{Ph} 52$ \\
\hline & \multirow[t]{2}{*}{ Meaning-making and identity in the making } & P1 & Ph6, Ph7, Ph11, Ph16, Ph22, Ph23, Ph31, Ph36, Ph60, Ph76 \\
\hline & & P2 & $\mathrm{Ph} 1, \mathrm{Ph} 11, \mathrm{Ph} 20, \mathrm{Ph} 42, \mathrm{Ph} 43, \mathrm{Ph} 49$ \\
\hline
\end{tabular}

P, participant; Ph, photo.

groups without belonging to any of these. Managing boundaries, whilst balancing one's own personal needs, is an ongoing struggle throughout the deployment. Ongoing conversations with yourself, reinforcing your role, identifying your own needs, analysing these and absolute internal locus of control are essential to maintain sanity. However, as this objective is achieved by the psychologist, an inevitable experience of isolation and loneliness dawns upon one. On the other hand, there is the isolation from everyone at home, family, friends and things:

'This is just when you get a parcel from home, which you rarely get. The first thing you look for is the letter. You don't even look for the snack, which you really need because you are deprived and you really crave things. But the first thing I did was unpack the cigarettes, and tried to find the letter, because my mom said she had sent a letter with news from home. The social worker took the photo and I didn't even notice, because I was so deep in thought. There was no calling home, no cell phone coverage, no contact.' (P1, Ph46)

Participant 2 explained her constant focus on maintaining professionalism, intentionally remaining separate from the group, having limited interaction, managing interactions and perceptions. The ongoing battle between being distant without disconnecting with people, and for most of the deployment feeling lonely and isolated was explained as follows:

'During this time I was focussed on just being professional. I went into this thing, I was remaining separate from the group. I cannot really talk to anyone, I just ate and I showered and did my work I had a lot of work that kept me busy 'till the evenings. I didn't really mingle, I was really a bit distant at this stage if I have to be honest with myself, and feeling very lonely.' (P2, Ph53)

\section{Dichotomies reflecting the beauty of the environment intertwined with the realities of war}

During the interview, participant 1 emphasised the constant dichotomies she was faced with, specifically the harshness of the environment compared to its beauty and having to keep weighing these opposite views within her. Constantly oscillating between one side of the continuum to the other on specific aspects and issues:

'This photo is just a photo of desolation, sadness. I used to always think, here is this people we are going to in this military in the middle of nowhere. Perfect little world, perfect perimeters, inside this imperfection.' (P1, Ph12)

Participant 2 explained how her view on the environment changed from earlier in the narrative towards the end as growth and change occurred in the broader narrative of the deployment. The beauty of the environment was one of the positive aspects of the deployment, which had a deep-seated impact on her, although similar to participant 1 , there was always an aspect of danger entangled with the beauty, also constant dichotomies in the surroundings:

'Sunsets in the guard tower. You can feel how the whole world becomes at peace, the light becomes softer, quieter, calmer. No one moves (because of the curfew and the war and that they kill people at night) but it still gives the illusion of peace the earth is alone and at peace with herself for those few minutes of sunset, she breathes really loud, you can feel her. I can feel me, I like to go to that same place, every day at the same time. My time to breathe, just after shower, I am clean, I am calm, I have eaten, I can just be. I can just long for faraway places, in awe of the 
beauty. I wonder if one day I will be able to have a place where I can watch the sunset every day when I am really old and feel this way again.' (P2, Ph43)

\section{Connectivity - Experiencing the 'band of brothers'}

Participants 1 and 2 reported the Christmas period during the deployment as a significant experience. Participant 1 refers to the connectivity and the sense of belonging experienced between soldiers during a deployment:

'It was Christmas, in the background there is a bench. I decorated all the benches with flowers. I got my family to send Christmas decorations and cake. I wanted to make Christmas special for my deployed family. I wanted to make everything Christmassy, and it was one of the best Christmases. I gave all of them something; I got a company to sponsor pens and gave it to them. I think I wanted to give them something so badly because they gave me so much.' (P1, Ph16)

Participant 2 mentioned very similar experiences with the integration of soldiers during a deployment, a sense of connection that she has never experienced outside of the military environment:

'It was Christmas just a month after we landed there. There was one sustainment flight that landed with us and all the parcels were there already. They packed all this Christmas stuff in there, the small Christmas tree; my parcels were wrapped in Christmas paper. We had no Christmas; I was the only one that had some stuff. I made presents for all the lady officers, I divided my snacks for everyone, from the paper they put over the boxes, I invited them on the morning of Christmas, and they all came in and we ate all the biscuits, most of the things we just ate there.' (P2, Ph24)

\section{Peacekeeping deployment experiences}

This theme reflects on the participants' experiences that relate particularly to PKOs. Four subthemes are thoroughly explained below.

\section{The mythical children, tainted with anger, living in a world of suffering}

Participants 1 and 2 reported similar emotions and frustrations and contradictions experienced in their interaction with the local population. Participant 1 particularly expressed the paradox and mixed emotions when looking at the kids when instead of children you see soldiers. They are exposed to things way beyond their years. Their eyes look into your soul:

'Two kids, the kids are so amazing, one is showing thumbs up and one is showing thumbs down. That is typical, you never know whether they are happy or just want something from you. They are the only symbols of purity and goodness, except for the animals of course, then you realise that they are already so tainted with anger and resentment. They are not kids.' (P1, Ph28)

Participant 2 explained how waiting is a big part of peacekeeping duties, waiting during patrols, waiting for handovers; she said that during this time, nothing clouds your mind, you are just there; however, during this time, there is the constant presence and focus on the children running around barefoot, hungry; it is just horribleness with the peacefulness. It does something to you. It changes something inside of you and you cannot change it back. Once you have seen it, you cannot unsee it; once you feel it, you cannot unfeel it:

'This little girl captured my attention. As I was walking around, buying dates, I bought half a $\mathrm{kg}$ of dates, and I ate half a $\mathrm{kg}$ of dates in 3 days which added to my weight gain. You could feel the sugar rush. It's like this girl was attracted to me, probably for obvious reasons, she walked with me the entire time, she would just hide behind things, she is beautiful, she has beautiful features, lighter in complexion, but to me she was beautiful, she had spirit, she was not like the other girls, she would talk to me, she had like a fire in her. She was angry when I left, all the joy was gone, because she was so angry because I left. I deserted her. Betrayed her trust. She saw hope in me and I couldn't give her anything. Bitter sweet. You are gorgeous my darling, don't let them steal the fire in your eyes. Don't allow them to force you into their mould, you are so much more than that.' (P2, Ph33)

\section{The hardship carried by scarred animals}

Participant 1 reflects on the suffering of the animals; the photos show how animals carry the burden of people. The godliness displayed in the way they help people; in spite of this, they also become victims in the struggle:

'Photos of the donkeys. The donkeys are the worst victims of the struggle. This one has so many scars, such a beautiful white donkey. It looks like tears are streaming from his eyes. I feel so sorry for them. I think I feel most sorry for the donkeys. The donkey will just die. Futility. There is nothing more that will happen. Futility.' (P1, Ph37)

Participant 2 emphasised the suffering of animals that were constantly observed within the country and the frustrations of being unable to do something:

'The donkey. I asked one of these ladies to allow me to sit on her donkey. I wanted to feel a little bit of what they feel. It was so sad. The donkey is so small, and you can feel that you are too heavy for it, eyes closed, I can feel the suffering, the pain, I felt so bad for doing this. You can feel every piece of his body. You can feel that he has surrendered, given up, you are supposed to do something. But there was nothing I could do, just nothing.' (P2, Ph44)

\section{The vulnerability of iron women}

Participant 1 explains the visible and ever-present physical workload the women carry, which far exceeds the normal load people are expected to carry, and it is done with so much grace. It is difficult to observe without enduring physical pain:

'Beautiful picture of the light shining. The sunlight is blessing these women. They work so hard, collecting wood, getting water, taking tea to men. They are the most unloved group of homo sapiens I have ever seen in my life. They are worse than the animals.' (P1, Ph30)

Participant 2 also expressed frustration with the paternal system and reflected on how difficult it was to witness a 
system where women are fulfilling a far different role than what they are used to:

'It is beautiful to me, because you can see the desert, you can see no colour, no nothing, and these beautiful women, on their donkeys, and the horrible thing of them working, but this photo is just beautiful, they stand out in this desert, besides these difficult circumstances, they are just beautiful in these bright colours. Just beautiful.' (P2, Ph41)

\section{Character of the country}

Both participants expressed their appreciation for the enriching experience of understanding a country so different from their own and the symbolism that could be drawn from so many occurrences. A shared similar experience between the two participants is cited below in the particular photos identified:

\begin{abstract}
'This photo I seem demure, because in this photo I had such an affinity for the store keeper. He makes the most beautiful shoes out of nothing. The shoes in Darfur are so important, because they carry the feet of people in this very barren place, they are beautiful, much more beautiful than the people, their clothes and they also are not as practical, but they almost seem unworldly.' (P1, Ph75)

'Beautiful. This is really one of my favourites. Symbolises the good things about the place and the people. Patience, age, dedication and this old, old man. Everything about him is special and unique. He measures your feet and he makes the shoes. Whatever pattern you want, and that is something that I learnt from that country. It's all of that and much, much more. Everything doesn't have to be size 6, you can find something that is especially for you. The right things will come to you.' (P2, Ph22)
\end{abstract}

\section{Unique female psychologist experiences}

This theme highlights the unique experiences of the participants' experiences, which relates particularly to the 'female' condition.

\section{Practising in a system of patriarchy}

Participant 1 explained the constant awareness of the metasystems within which the deployed female psychologist operates. The overarching male dominance within the deployed country, with the characteristic patriarchy associated with the military; finally, the further systems within the military where medical personnel also traditionally fulfil a secondary supportive function to the core army male dominant services:

'We women were not allowed to be part of the prayers, but the men were. So fascinating that these people have such huge religious underpinnings, but also this strong hatred...just all about falseness.' (P1, Ph29).

Participant 2 explained how the constant reminders that you are a woman in all the spheres create an awareness that you are less worthy, with a response of defensiveness, and a need to prove yourself constantly:

'This photo represents the male superiority. It's like even though they don't know anything they are above you, above anyone, or anything else, and I don't know where they get that sense of righteousness. What feeds into that system.' (P2, Ph6)

\section{The female soldier}

Participant 1 reported the sense of strength that she experienced, with her weapon being a symbol representing the soldier. She furthermore explained the sense of pride she took in taking care of the rifle, carrying it and the values of being a soldier being entrenched in her as the deployment progressed:

'This is tinkerbell my rifle. This is my spot in the bunker..and ja... uhm...this was just the perspective from the rifle. We had to stand there every morning and every evening, just quietly looking in your direction. I loved my rifle and I took her everywhere...well we were supposed to...but I loved my rifle. I wonder where she is now.' (P1, Ph49)

Participant 2 specifically mentioned the boots of a soldier as a symbol of soldiering, especially female soldiering. The participant also emphasised the constant drive to prove oneself as a soldier, a part of the group, even if it meant that you had to do more, work harder:

'Another photo of an angle of a soldier in the Mamba that I took. The boots, I don't know how to explain it. The boots is the essence of soldiering. It was a female soldier's boot. They suffer, and on the one side you don't want to feel sorry for them, because we want them to be strong, because you want to be proud of them, but you can see they suffer much more than the guys. Everything about a soldier is captured by their boots, we walk in our boots every day, every mile is reflected, your boots have been to so many different places, with so many different people, every dent, every hole, it's all in there. Other people have different shoes for different occasions, soldiers have only one, we walk with it, work with it, run with it, sleep with it. If boots could talk ... You can see everything about a soldier when you look at their boots, discipline, years of service, it is in the way you polish, the way you tie your laces. It is tough and real. I love it.' (P2, Ph31)

\section{Touching the hearts and hands of people - Making a tangible difference}

Participant 1 explained how special it was to make a difference, to feel useful and humbled by the experience of serving people who faced so much suffering and difficulty:

'Picture of me and a Sudanese woman, we had blankets sent from SA to do a project with the elderly. We met with an NGO and they showed us houses of terminally ill people and we gave them blankets. Most of them just lie on the floor with no blankets or mattresses. This photo is so special they just thanked you, grab you and hold on to you.' (P1, Ph32)

Participant 2 said that she experienced the greatest sense of fulfilment of her life during the deployment, because of the visible difference that could be made in the deployed environment:

'I could see exactly what people needed. I just experienced the greatest sense of fulfilment that I have experienced in my entire life.' (P2, Ph52)

\section{Meaning-making and identity in the making}

Participant 1 explained how she was faced with an overwhelming presence of paradoxes and juxtapositions 
throughout the deployment experience. The 'harshness' of the environment versus the 'beauty' of the environment. The paradoxes between 'destruction' and 'order' in the war-torn peacekeeping environment. She experienced an ongoing critical analysis of everything around her. Symbols of hands and feet were visible through the different phases of deployment; through the extremity of the challenges met, she managed to make meaning of the experience and furthermore integrate this with her existing identity. She walked away a soldier, with a deep understanding of the intensity and seriousness associated with the military, a significant part of a unique community:

'This is most probably my favourite photo of all time. This photo symbolises so much, this photo is the photo that transformed me, in one moment one person and after this experience another person, although I have always been that person. After this experience I was a changed person. I trusted myself, I knew who I was, I felt, I wept, I cried.' (P1, Ph76)

Participant 2 explained how she experienced a sense of 'patience' in the desert, where it is not about the goal that you need to achieve but how you get there that matters. It is the wait. It is the being. Every breath of air, every minute, contained a lesson and the vastness, isolation challenged her but simultaneously forced her to experience a deep sense of meaningfulness.This challenged the way she viewed herself, how she existed and connected to the world, and it had an irrevocable impact on her identity:

'Our last trip home. So much fun, joy and happiness. I have never felt this light in my entire life. I felt free, like I could jump and the air of the world would just lift me up and suck me into the core of its existence, I was one with the earth, with life itself. I was just me, happy, free, independent, exactly where I needed to be, who I needed to be.' (P2, Ph49)

\section{Discussion}

As reflected in the results (Figure 1), the deployment experiences of female psychologists share similarities with existing research on soldiers' deployment experiences as well as soldiers' experiences on PKO. However, there are some novel narratives that are critical to enhance our understanding of deployed female military psychologists within the operational area.

In line with previous research regarding the deployment experiences, participants in this study reported experiences of confinement and isolation (Bartone \& Adler, 2000; Coll, Weiss, \& Yarvis, 2011; King, King, Vogt, Knight, \& Samper, 2006). The complexity of the isolation reported by the participants was experienced on three different levels, namely: (1) the military context as a 'separate' arm of service from the serving battalion, (2) on a professional level, managing boundaries as a psychologist, as well as on a (3) personal level referring to the experienced separation from family. Bartone and Adler (2000) also emphasised the feeling of 'separateness' experienced by a medical task force during a 6-month Sinai peacekeeping deployment. Research from Iraq and Afghanistan suggests that isolation or a sense of aloneness are amongst the common challenges soldiers experience whilst being deployed (Miller \& Warner, 2013). Isolation was also reported by members specifically as a stressor during PKOs (Britt \& Adler, 2003).

Peacekeeping deployment experiences of participants correspond with existing research on soldiers' experiences of witnessing the suffering of the civilian local population in PKOs, which has been documented as heart-wrenching for many, especially observing the impact of the conflict on children (Britt \& Adler, 2003; Heinecken \& Ferreira, 2012b). The participants experienced similar agonising illustrations of the suffering of animals, children and women. The powerlessness to change the circumstances of the local community contributes to the challenges experienced by soldiers during PKOs. Often, the soldiers are unable to reach out to the community; however, in the case of psychologists, the need for contact and care are redirected towards fellow deployed members. The shared experiences of war tend to create a strong connection, need for social bonding and contact (Mouthaan, Euwema, \& Weerts, 2005). This was evident in the participants' experience of social belonging and connectedness to the deployed contingent reflected in the findings. The unit cohesion reflected in the findings serves as confirmation that an increased sense of belonging serves as a factor that reduces the contextual stressors experienced within the peacekeeping context (Van Dyk, 2009).

The experiences of female psychologists in this study contains both confirmatory and novel narratives. Research suggests that psychologists during operational deployment experience challenges like adaptation to the environment, military culture, separation from family, limited control, professional isolation, ethical dilemmas and constant awareness of death (Linnerooth et al., 2011). Female psychologists are likely to face additional military attitudinal barriers, influenced by societal traditional ideologies that have to be overcome to increase cohesiveness with the contingent (Ghimire, 2017; Laurence et al., 2016). This study similarly conceptualises the impact of the extended deployment of a female psychologist as the internalisation of a belief system, values and a lifestyle mostly understood amongst fellow soldiers, which differs from the mainstream civilian psychology fraternity (Coll et al., 2011). This is similar to the experience of participants in the study who went to great extents to internalise the military culture and all the symbols that represent it like weapons and boots. The impact of operational deployment is more pronounced in female health care practitioners, and furthermore unique in the manner in which it is experienced not necessarily only in the severity of the impact (Gibbons, Hickling, Barnett, Herbig-Wall, \& Watts, 2012). This is especially visible in the in-depth analysis the deployed female psychologists conducted on the various aspects of the military culture and their own interaction and 'fit' within this community. It resulted in constant measurement against the generally accepted standards within a peacekeeping deployment. Similar to the reports of participants in this study, these experiences become more emphasised during an 
extended length of deployment, more visible after a 6-month period; however, female soldiers more than their male counterparts tend to become habituated to the deployed environment, which reduces the impact of deployment length on female soldiers (Adler, Huffman, Bliese, \& Castro, 2005). This explains the positive experiences of identity and meaning-making reported after the 7-month period of deployment; it also intertwines with the constant need for meaning-making expressed by psychologists in general and alludes to a unique dimension experienced by female psychologists on an extended deployment. Although this factor could contribute to the successful adjustment of a deployed female psychologist, it could have repercussions on the reintegration of the female psychologist postdeployment, possibly extending the adjustment period required.

\section{Limitations of the study}

The study only speaks of the experiences of female military psychologists during $\mathrm{PKO}$; the comparison of the uniqueness of these experiences in relation to the experiences of male military psychologists could add value in the further understanding of PKO experiences. The study only focussed on one deployment area. Environmental factors and the varying nature of the deployments in other deployment areas could impact on the experiences of soldiers.

\section{Conclusions, recommendations and practical implications for psychologists}

The aim of this article was to describe the in-depth experiences of female, SANDF psychologists during a PKO in Darfur. Findings show similarities with the experiences of soldiers in various deployment settings and specifically so to those experiences of soldiers during PKO. However, unique experiences of female psychologists were documented as the creation of identity and meaning, the extended identity of being a female soldier and constant awareness of the patriarchal system they functioned within.

Future research on the experiences of female psychologists during military deployment should explore the experiences pre-, during and post-deployment periods to differentiate between the challenges during the different phases of deployment. Members' typical responses to these experiences can also be investigated further. A comparison of the experiences of male and female psychologists during military deployments could further enhance the understanding of this unique situation in which military psychologists find themselves.

Practical implications for psychologists include expanding the support given to deployed female psychologists, before, during and after deployment. Based on these findings, appropriate support plans could be developed to address the various challenges identified.

\section{Acknowledgements}

The authors wish to thank Maj R.A. du Toit for his role as objective researcher in order to triangulate our data.

\section{Competing interests}

The authors have declared that no competing interests exist.

\section{Author's contributions}

All authors contributed equally to this work.

\section{Funding information}

This research received no specific grant from any funding agency in the public, commercial, or not-for-profit sectors.

\section{Data availability statement}

Data sharing is not applicable to this article as no new data were created or analysed in this study.

\section{Disclaimer}

The views and opinions expressed in this article are those of the authors and do not necessarily reflect the official policy or position of any affiliated agency of the authors.

\section{References}

Adler, A.B., Huffman, A.H., Bliese, P.D., \& Castro, C.A. (2005). The impact of deployment length and experience on the well-being of male and female soldiers. Journal of Occupational Health Psychology, 10(2), 121-137. https://doi.org/10.1037/10768998.10.2.121

Babbie, E., \& Mouton, J. (2010). The practice of social research (10th edn.). Cape Town: Oxford University Press Southern Africa.

Bartone, P.T., Adler, A.B., \& Vaitkus, M.A. (1998). Dimensions of psychological stress in peacekeeping operations. Military Medicine, 163(9), 587-593. https://doi. org/10.1093/milmed/163.9.587

Bartone, P.T., \& Adler, A.B. (2000). Cohesion over time in a peacekeeping medical task force. Military Psychology, 11(1), 85-107.

Born, J.A., \& Zamorski, M.A. (2019). Contribution of traumatic deployment experiences to the burden of mental health problems in Canadian Armed Forces personnel: Exploration of population attributable fractions. Social Psychiatry and Psychiatric Epidemiology, 54(2), 145-156. https://doi.org/10.1007/s00127-0181562-6

Britt, T.W., \& Adler, A.B. (2003). The psychology of the peacekeeper: Lessons from the field. Westport, CT: Praeger.

Campbell, D.J., \& Nobel, O.B.Y. (2009). Occupational stressors in military service: A review and framework. Military Psychology, 21(2), 47-67.

Chapman, P.L., Cabrera, L.D., Varela-Mayer, C., Baker, M.M., Elnitsky, C., Figley, C., Mayer, L.P. (2012). Training, deployment preparation, and combat experiences of deployed health care personnel: Key findings from deployed U.S. army combat medics assigned to line units. Military Medicine, 177(3), 270-277. https://doi. org/10.7205/MILMED-D-11-00305

Coll, J.E., Weiss, E.L., \& Yarvis, J.S. (2011). No one leaves unchanged: Insights for civilian mental health care professionals into the military experience and culture. Social Work in Health Care, 50(7), 487-500. https://doi.org/10.1080/00981389.2 010.528727

Denzin, N.K., \& Lincoln, Y.S. (1994). Handbook of qualitative research. Thousand Oaks: Sage.

Hutabarat, L.F. (2017). Indonesian female peacekeepers in the United Nation peacekeeping mission. Jurnal Pertahanan, 3(3), 185-206. https://doi. org/10.33172/jp.v3i3.214

Ghimire, B. (2017). Contributions and challenges: Female participations in UN peacekeeping missions. International Journal of Humanities and Social Science, 7(3), 207-213.

Gibbons, S.W., Hickling, E.J., Barnet, S.D., Herbig-Wall, P.L., \& Watts, D.D. (2012) Gender differences in response to deployment among military health care providers in Afghanistan and Iraq. Journal of Women's Health, 21(5), 496-504. https://doi.org/10.1089/jwh.2011.3097 
Guba, E.G., \& Lincoln, Y.S. (1994). Competing paradigms in qualitative research. In N.K. Denzin \& Y.S. Lincoln (Eds.), Handbook of qualitative research (pp. 105-117). Thousand Oaks, CA: Sage.

Heinecken, L., \& Ferreira, R. (2012a). South Africa's role in peace operations in Africa (Part I). African Security Review, 21(2), 20-35. https://doi.org/10.1080/10246029 .2011 .641686

Heinecken, L., \& Ferreira, R. (2012b). South Africa's role in peace operations in Africa (Part II). African Security Review, 21(2), 36-49. https://doi.org/10.1080/10246029 .2011.641687

Heinecken, L., \& Ferreira, R. (2012c). South Africa's role in peace operations in Africa (Part III). African Security Review, 21(2), 50-60. https://doi.org/10.1080/1024602 9.2011 .641688

Heinecken, L. (2016). Conceptualising the tensions evoked by gender integration in the military: The South African case. Armed Forces and Society, 43(2), 202-220. https://doi.org/10.1177/0095327X16670692

Johnson, W.B. (2008). Top ethical challenges for military clinical psychologists. Military Psychology, 20(1), 49-62. https://doi.org/10.1080/08995600701753185

Johnson, W.B., \& Kennedy, C.H. (2010). Preparing psychologists for high-risk jobs: Key ethical considerations for military clinical supervisors. Professional Psychology: Research and Practice, 41(4), 298-304

Kennedy, C.H., \& Zilmer, E.A. (2012). Military psychology: Clinical and operational applications (2nd edn.). New York: Guilford Press.

Kgosana, M.C., \& Van Dyk, G.A.J. (2011). Psychosocial effects of conditions of military deployment. Journal of Psychology in Africa, 21(2), 323-326. https://doi.org/10.1 080/14330237.2011.10820464

King, A.C. (2013). The female soldier. Strategic Studies Institute. United States Army War College Publications. Retrieved from https://pdfs.semanticscholar.org/fcce/24a0b8 fc8577300ff517b47145cc5f0baf6.pdf

King, L.A., King, D.W., Vogt, D.S., Knight, J., \& Samper, R.E. (2006). Deployment risk and resilience inventory: A collection of measures for studying deployment-related experiences of military personnel and veterans. Military Psychology, 18(2), 89-120. https://doi.org/10.1207/s15327876mp1802_1

Koopman, R., \& Van Dyk, G.A.J. (2012). Peacekeeping operations and adjustment of soldiers in Sudan: Peace in the minds and hearts of soldiers. African Journal of Conflict Resolution, 12(3), 53-76.

Laurence, J.H., Milavec, B.L., Rohall, D.E., Ender, M.G., \& Matthews, M.D. (2016) Predictors of support for women in military roles: Military status, gender and political ideology. Military Psychology, 28(6), 488-497. https://doi.org/10.1037/ mil0000142

Linnerooth, P.J., Mrdjenovich, A.J., \& Moore, B.A. (2011). Professional burnout in clinical military psychologists: Recommendations before, during, and after deployment. Professional Psychology: Research and Practice, 42(1), 87-93. https://doi.org/10.1037/a0022295

Maitra, S. (2013). Women and war: Women in combat and the internal debate in the field of gender studies. viewed n.d., from, https://www.semanticscholar.org/ paper/Women-and-War\%3A-Women-in-combat-and-the-internal-in-Maitra/ d4cf5f89ac84681d086229bbfb510f3a78c4c1a9
Mark, D.D., Conelly, L.M., Hardy, M.D., Robinson, J., Jones, C.C., \& Streett, T.A. (2009). Exploring deployment experiences of army medical department personnel. Military Medicine, 174(6), 631-636. https://doi.org/10.7205/ personnel. Military

Matthews, M.D., Morten, G.E., Laurence, J.H., \& Rohall, D.E. (2009). Role of group affiliation and gender on attitudes toward women in the military. Military Psychology, 21(2), 241-251. https://doi.org/10.1080/08995600902768750

Mattocks, K.M., Haskell, S.G., Krebs, E.E., Jusice, A.C., Yano, A.M., \& Brandt, C. (2012). Women at war: Understanding how women veterans cope with combat and military sexual trauma. Social Science and Medicine, 74(4), 537-545. https://doi. org/10.1016/j.socscimed.2011.10.039

McCauley, M., Hughes, J.H., \& Liebling-Kalifani, H. (2008). Ethical considerations for military clinical psychologists: A review of selected literature. Military Psychology, 20(1), 7-20. https://doi.org/10.1080/08995600701753128

Miller, P.E., \& Warner, B. (2013). Postdeployment experiences of military mental health providers. Military Medicine, 178(12), 1316-1321. https://doi.org/10.7205/ MILMED-D-13-00023

Moore, B.A., \& Reger, G.M. (2006). Clinician to frontline soldier: A look at the roles and challenges of army clinical psychologists in Iraq. Journal of Clinical Psychology, 6(3), 395-403. https://doi.org/10.1002/jclp.20218

Mouthaan, J., Euwema, M.C., \& Weerts, J.M.P. (2005). Band of brothers in U.N. peacekeeping: Social bonding among Dutch peacekeeping veterans. Military Psychology, 17(2), 101-114. https://doi.org/10.1207/s15327876mp1702_3

Neuendorf, K.A. (2002). The content analysis guidebook. CA: Sage.

Orme, G.J., \& Kehoe, J. (2014). Reservists in a postconflict zone: Deployment stressors and the deployment experience. Military Medicine, 179(2), 137-142. https://doi. org/10.7205/MILMED-D-13-00439

Patton, M.Q. (2002). Qualitative research and evaluation methods. CA: Sage.

Raju, M.S.V.K. (2014). Psychological aspects of peacekeeping operations. Industrial Psychiatry Journal, 23(2), 149-156. https://doi.org/10.4103/0972-6748.151693

Rollero, C., \& De Sanctis, S. (2019). The experience of male soldiers during peacekeeping missions: A qualitative study. Peace and Conflict: Journal of Peace Psychology, 26(1), 100-104. https://doi.org/10.1037/pac0000431

Simic, O. (2010). Does the presence of women really matter? Towards combating male sexual violence in peacekeeping operations. International Peacekeeping, 17(2) 188-199. https://doi.org/10.1080/13533311003625084

Tarrash, R., Lurie, O., Yanovich, R., \& Moran, D. (2011). Psychological aspects of the integration of women into combat roles. Personality and Individual Differences, 50(2), 305-309. https://doi.org/10.1016/j.paid.2010.10.014

Visagie, E. (2018). Female combatants in peacekeeping operations: Examining the impact of the South African gender policy. Commandant's Research Paper, Security and Defence Studies Programme, SANDF Defence College, Pretoria: South African National Defence Force.

Van Dyk, G.A.J. (2009). The role of military psychology in peacekeeping operations: The South African National Defence Force as an example. Scientia Militaria, 37(1), 113-135. https://doi.org/10.5787/37-1-62 